DEMONSTRATIO MATHEMATICA

Vol XXXIII No 1

\title{
Vu Van Hung
}

THE STABILITY OF THE DIFFERENCE SCHEMA APPROXIMATING CAUCHY'S PROBLEM FOR THE SECOND ORDER PARABOLIC EQUATION WITH VARIABLE COEFFICIENTS IN $\mathrm{L}_{2}$

\section{Introduction}

In [6] a class of differenoe sohemas was presented which allow us to approximate parabolic problem for equation of second order in $I_{2}$. Those schemas are open and unconditionalis stable. In [6] only the case with constant coefficients in space vartables were considered. In the present work we will deal with the oase of variable coefficients depending on the space and time parameters. We shall consider the differenco sohema for solving the stability problem

$(1.1)$

$$
\left\{\begin{array}{l}
\frac{\partial u}{\partial t}=a(x, t) \frac{\partial^{2} u}{\partial x^{2}}+b(x, t) \frac{\partial u}{\partial x}+c(x, t) u+f(x, t), \\
(x, t) \in R \times(0, T), \\
U(x, 0)=\varphi(x), \quad \varphi \in C(R) .
\end{array}\right.
$$

We aseume that the functions $a(x, t), b(x, t), c(x, t), f(x, t)$ are elements of the spaoe $C(R,(O, T))$ and $a(x, t) \geqslant a_{0}>0$. On the rectangular grid

$$
R_{h \tau}^{2}:=\{(x, t): x=m h, t=a \tau, \quad m, n \in Z, \quad N \tau=T, h, \tau>0\}
$$

we coneider the following differenoe sohema 


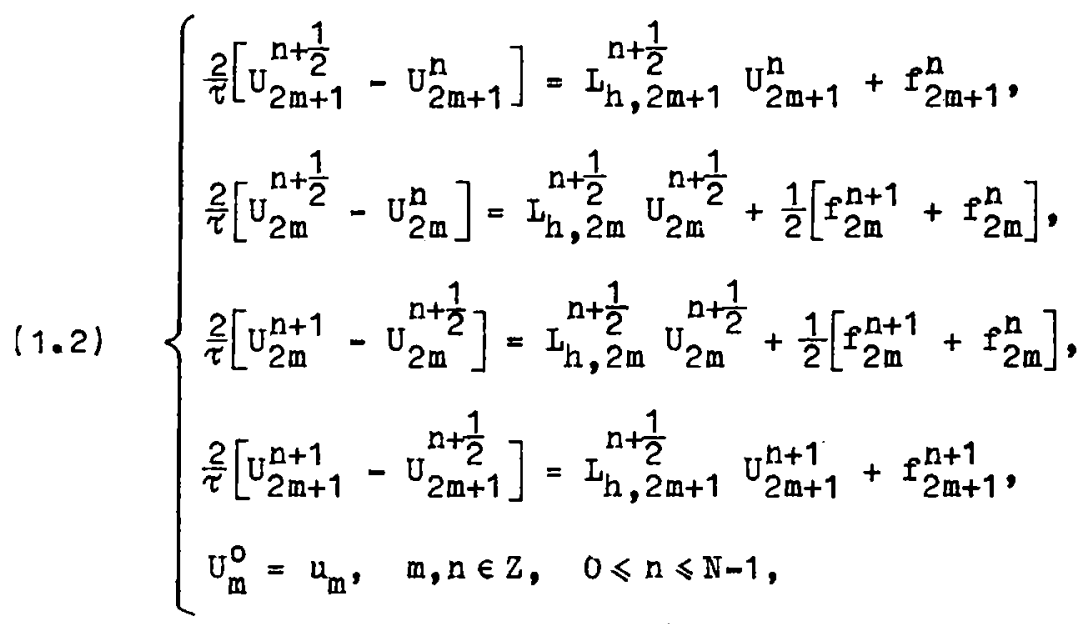

where the difference operator $\left(\left(L_{h}^{n}, m^{y}\right)_{k}\right.$ is defined on the number seguenoes as followe

$$
\begin{gathered}
\left(I_{h, m^{\prime}}^{n}\right)_{k}:=I_{h, m^{y}}^{n}:=a_{m}^{n}\left[\nabla_{k-1}-2 y_{k}+y_{k+1}\right]+b_{m}^{n} \frac{1}{2 h}\left[y_{n+1}-y_{n-1}\right]+c_{m}^{n} y_{k}, \\
\forall(m, n, k), \quad 2 n \in Z, \quad m, n \in Z,
\end{gathered}
$$

and $U_{m}^{n}:=u(m h, n \tau), Z$ - the set of integers.

2. The stability of the differenos schema (1.2) for the problem (1.1)

To investigate the stability of this problem we prove the following theorem.

Th $\mathrm{h}$ or e $\mathrm{m}$ 2.1. The sequenoe $\left\{U_{m}^{n}\right\}_{\substack{m, n \in Z \\ 0<n<N}}$ satisfies the system of difference equations (1.2) if and only if this sequence satisfies the relation defined by the following difference schema

(2.1)

$$
\left\{\begin{array}{l}
\frac{1}{2}\left[U_{m}^{n+1}-U_{m}^{n}\right]=\frac{1}{2}\left[I_{h, m}^{n+\frac{1}{2}} U_{m}^{n+1}+f_{m}^{n+1}\right]+\frac{1}{2}\left[I_{h, m}^{n+\frac{1}{2}} U_{m}^{n}+f_{m}^{n}\right], \\
U_{m}^{0}=\varphi_{m}, \quad m, n \in Z, \quad 0 \leqslant n \leqslant N-1 .
\end{array}\right.
$$


P r o o $f$. First we show that if the sequenos $\left\{U_{m}^{n}\right\}$ satiefies (1.2), then it satisfies (2.1). Summing up the seoond and third equation of (1.2) and dividing by 2 we obtain

$$
\frac{1}{\tau}\left[U_{2 m}^{n+1}-U_{2 m}^{n}\right]=I_{h, 2 m}^{n+\frac{1}{2}} U_{2 m}^{n+\frac{1}{2}}+\frac{1}{2}\left[f_{2 m}^{n+1}+f_{2 m}^{n}\right],
$$

and substracting side by side we obtaln

$$
U_{2 m}^{n+\frac{1}{2}}=\frac{1}{2}\left[U_{2 m}^{n+1}+U_{2 m}^{n}\right], \quad m \in Z
$$

On both sides of the above equations we act with the operator $I_{h, 2 m}^{n+1 / 2}$ and the obtained result $I_{h, 2 m}^{n+1 / 2} U_{2 m}^{n+1 / 2}$ we substitute to $(2.2)$, and we obtain

$$
\begin{aligned}
& \text { (2.3) } \frac{1}{2}\left[U_{2 m}^{n+1}-U_{2 m}^{n}\right]=\frac{1}{2} \dot{L}_{h, 2 m}^{n+\frac{1}{2}}\left[U_{2 m}^{n+1}+U_{2 m}^{n}\right]+\frac{1}{2}\left[f_{2 m}^{n+1}+f_{2 m}^{n}\right]= \\
& =\frac{1}{2}\left[L_{h, 2 m}^{n+\frac{1}{2}} U_{2 m}^{n+1}+f_{2 m}^{n+1}\right]+\frac{1}{2}\left[L_{h 2 m}^{n+\frac{1}{2}} U_{2 m}^{n}+f_{2 m}^{n}\right] .
\end{aligned}
$$

Similarly, adding first and fourth equation of the syotem (1.2), we obtain

$$
\text { (2.4) } \begin{aligned}
\frac{1}{\tau} & {\left[U_{2 m+1}^{n+1}-U_{2 m+1}^{n}\right]=\frac{1}{2} I_{h, 2 m+1}^{n+\frac{1}{2}}\left[U_{2 m+1}^{n+1}+U_{2 m+1}^{n}\right]+\frac{1}{2}\left[f_{2 m+1}^{n+1}+f_{2 m+1}^{n}\right]=} \\
& =\frac{1}{2}\left[I_{h, 2 m+1}^{n+\frac{1}{2}} U_{2 m+1}^{n+1}+f_{2 m+1}^{n+1}\right]+\frac{1}{2}\left[I_{h, 2 m+1}^{n+\frac{1}{2}} U_{2 m+1}^{n}+f_{2 m+1}^{n}\right] .
\end{aligned}
$$

Hence, from (2.3) and (2.4) we obtain

$$
\frac{1}{\tau}\left[U_{m}^{n+1}-U_{m}^{n}\right]=\frac{1}{2}\left[I_{h m}^{n+\frac{1}{2}} U_{m}^{n+1}+f_{m}^{n}\right]+\frac{1}{2}\left[f_{m}^{n}+I_{h m}^{n+\frac{1}{2}} U_{m}^{n}\right] .
$$

This schema together with the condition $U_{m}^{O}=\phi_{m}$ for $m \in Z$ gives the difference sohema (2.1).

To show that the sequence $\left\{\mathrm{U}_{m}^{m+1 / 2}\right\}$ defined by the sohema (2.1) satiafies (1.2) we introduce an auxillary sequenoe $\left\{v_{m}^{n+1 / 2}\right\}$ defined as follows 
$(2.5)$

$$
U_{2 m+1}^{n+\frac{1}{2}}=U_{2 n+1}^{n}+\frac{\tau}{2}\left[I_{h, 2 m+1}^{n+\frac{1}{2}} U_{2 m+1}^{n}+e_{2 m+1}^{n}\right] \text {, }
$$

(2.6)

$$
U_{2 m}^{n+\frac{1}{2}}=\frac{1}{2}\left(U_{2 m}^{n+1}+U_{2 m}^{n}\right) \text {, for } m, n \in Z \text {. }
$$

Using (2.6) and (2.1) we obtain

$$
\begin{gathered}
\frac{2}{\tau}\left[U_{2 m}^{n+\frac{1}{2}}-U_{2 m}^{n}\right]=\frac{1}{\tau}\left[U_{2 m}^{n+1}-U_{2 m}^{n}\right]= \\
=\frac{1}{2}\left[I_{h, 2 m}^{n+\frac{1}{2}} U_{2 m}^{n}+f_{2 m}^{n}\right]+\frac{1}{2}\left[I_{h}^{n+\frac{1}{2}} U_{2 m}^{n+1}+f_{2 m}^{n+1}\right] .
\end{gathered}
$$

From the linearity of $L_{h, 2 m}^{n+1 / 2}$ and $(2.6)$ we have

(2.7) $\frac{2}{\tau}\left[U_{2 m}^{n+\frac{1}{2}}-U_{2 m}^{n}\right]=L_{h, 2 m}^{n+\frac{1}{2}} U_{2 m}^{n+\frac{1}{2}}+\frac{1}{2}\left[f_{2 m}^{n+1}+f_{2 m}^{n}\right]$.

Similarly

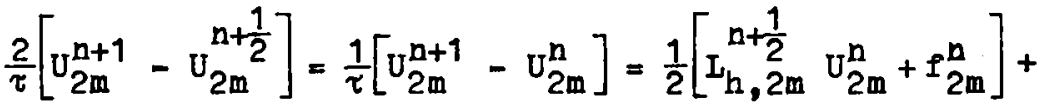

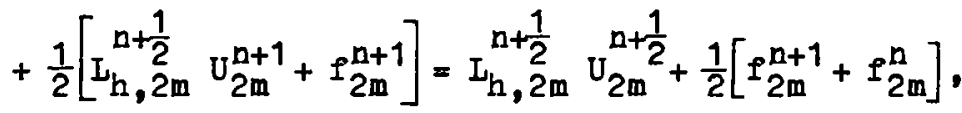

that is

(2.8) $\frac{2}{\tau}\left[U_{2 m}^{n+1}-U_{2 m}^{n+\frac{1}{2}}\right]=I_{h, 2 m}^{n+\frac{1}{2}} U_{2 m}^{n+\frac{1}{2}}+\frac{1}{2}\left[f_{2 m}^{n+1}+f_{2 m}^{n}\right]$.

Uaing definitions (2.5), we obtain

$\frac{2}{\tau}\left[U_{2 m+1}^{n+1}-U_{2 m+1}^{n+\frac{1}{2}}\right]=\frac{2}{\tau}\left[U_{2 m+1}^{n+1}-U_{2 m+1}^{n}\right]-L_{h, 2 m+1}^{n+\frac{1}{2}} U_{2 m+1}^{n}-f_{2 m+1}^{n}$.

Similarly, using (2.1), we obtain

$$
\frac{2}{\tau}\left[U_{2 m+1}^{n+1}-U_{2 m+1}^{n+\frac{1}{2}}\right]=2\left[\frac{1}{2}\left(u_{h}^{n+\frac{1}{2}} \quad U_{2 m+1}^{n+1}+f_{2 m+1}^{n+1}\right)+\right.
$$


Cauchy 's problem

5

$$
\begin{gathered}
\left.+\frac{1}{2}\left(I_{h, 2 m+1}^{n+\frac{1}{2}} U_{2 m+1}^{n}+f_{2 m+1}^{n}\right)\right]-I_{h, 2 m+1}^{n+\frac{1}{2}} U_{2 m+1}^{n}-f_{2 m+1}^{n}= \\
=I_{h, 2 m+1}^{n+\frac{1}{2}} U_{2 m+1}^{n+1}+f_{2 m+1}^{n+1},
\end{gathered}
$$

that is

(2.9) $\frac{2}{\tau}\left[U_{2 m+1}^{n+1}-U_{2 m+1}^{n+\frac{1}{2}}\right]=I_{h, 2 m+1}^{n+\frac{1}{2}} U_{2 m+1}^{n+1}+e_{2 m+1}^{n+1}$.

From formula (2.5) it follows that

$$
\frac{2}{\tau}\left[U_{2 m+1}^{n+\frac{1}{2}}-U_{2 m+1}^{n}\right]=I_{h, 2 m+1}^{n+\frac{1}{2}} U_{2 m+1}^{n}+f_{2 m+1}^{n} \bullet
$$

Hence Theorem 2.1 has been proved.

This theorem is important, because it reduces the investgations of the stability of schema (1.2) to the stability of schema $(2.1)$.

First, we can write the schema (2.1) In the canonical form. To this aim we denote

$$
\hat{U}:=U_{m}^{n+1}, U:=U_{m}^{n}, \quad U_{t}:=\frac{U_{m}^{n+1}-U_{m}^{n}}{\tau}, \hat{f}:=e_{m}^{n+1},
$$

$f:=f_{m}^{n}, U^{0}:=U_{m}^{0}, \quad \varphi_{t}=\varphi_{m}, \bar{t}=t n+\frac{1}{2} \tau$, for $m, n \in Z, 0 \leqslant n \leqslant N-1$.

Then (2.1) takes the form

$(2.10) \quad U_{t}=\frac{1}{2} I(\bar{t})(\hat{U}+U)+\frac{1}{2}(\hat{f}+f), \quad U^{0}=\varphi_{0}$

Using the identity

$$
\hat{U}=U+\tau \frac{\hat{U}-U}{\tau}=U+\tau U_{t} \text {, }
$$

we can write $(2.10)$ in the form

$$
U_{t}=\frac{1}{2} L(\bar{t})\left[U+\tau U_{t}+U\right]+\frac{1}{2}(\hat{f}+f), \quad U^{0}=\varphi,
$$

that is

$$
\begin{gathered}
\left(E-\frac{\tau}{2} I(\bar{t})\right) U_{t}-I(\bar{t}) U=f, \quad U^{0}=\varphi, \\
-19=
\end{gathered}
$$


in other words

$$
B U_{t}+A U=f, \quad U^{0}=\varphi \text {, }
$$

where $B:=E+\frac{\tau}{2} A, A:=-I(\bar{t})$.

To investigate the stability of this problem, we apply Theorem 10.14 in [5]. We formulate this fact as the following the orem.

$T h \theta \circ r \theta m$ 2.2. If the coeffioients of equation $(1.1)$ and the funotion $f(x, t)$ are continuous with respect to $x$ and $t$, and bounded in such a way that

$$
\frac{\partial a(x, t)}{\partial t} \in C(R,(0, T)) \text {, }
$$

then there exists $\tau_{*}$, depending only on the norm of ooeffiolents, such that for $\tau \in\left(0, \tau_{*}\right)$ the schema $(1.2)$ is unoonditionalis atable.

P r o of. By Theorem 2.1, the schema (1.2) is equivalent to sohema (2.1), whose unconditional stability is proved, o.g. in $[5]$, Th. 10.14.

3. The stability of differenoe sohemes for solving the problem of Cauohy for the parabollo equationg of order 2 with magy space variables

We consider the following initial problem

$(3.1)$

$$
\left\{\begin{array}{l}
\frac{\partial u}{\partial t}+I u=f(x, t), \quad(x, t) \in R^{M} \times(0, T), \\
u(x, 0)=\varphi(x), \quad x \in R^{M},
\end{array}\right.
$$

where $I$ is an elliptic operator, $I \in\left(C^{2}\left(R^{M}\right), C\left(R^{M}\right)\right)$, defined by

Iu $:=-\sum_{i, j=1}^{M} \frac{\partial}{\partial x_{1}}\left(a_{1 j}(x, t) \frac{\partial u}{\partial x_{j}}\right)+\sum_{1=1}^{M} b_{1}(x, t) \frac{\partial u}{\partial x_{1}}+o(x, t) u$. 
The differenoe soheme approximating (3.1) will be oonstructed on the paralleleptped grid $R_{h \tau}^{M}=R_{h}^{M} \times \omega_{\tau}$ with $R_{h}^{M}:=\left\{x \in R^{M}: x=\right.$ $\left.=\left(m_{1} h_{1}, \ldots, m_{M} h_{M}\right), m_{1}, \ldots, m_{M} \in Z\right\}, h:=\max _{1 \leqslant i \leqslant M} h_{1}, h_{1}, \ldots, h_{M} \geqslant h_{0}>0$, and $\omega_{\tau}:=\{t=n \tau, n=0, \ldots, N, N \tau=T)$, where ${ }^{1 \leqslant j} \partial_{10}, \bar{\partial}_{1}(1=\overline{1, M})$ we denote the difference operators

$$
\begin{array}{ll}
\partial_{i} v(x)=\frac{1}{h_{1}}\left[v\left(x+\theta_{1} h_{i}\right)-v(x)\right], & \forall x \in R^{M}, \\
\overline{\partial_{1} v}(x)=\frac{1}{h_{1}}\left[v(x)-v\left(x-\theta_{i} h_{i}\right)\right], \quad \forall x \in R^{M},
\end{array}
$$

for $1=\overline{1, M} ; \theta_{1}, \ldots, \theta_{m}$ denote the versors of the respective axes. Let $I_{h}^{0}, I_{h}, L_{h}^{1}$ denote the differenoe operators defined as follows

$$
\begin{aligned}
& I_{h}^{0} v(x):=-\frac{1}{2} \sum_{1, j=1}^{M}\left[\partial_{i}\left(a_{1 j}(x) \bar{\partial}_{j} v(x)+\bar{\partial}_{i}\left(a_{i j}(x) \partial_{j} v(x)\right)\right],\right. \\
& I_{h}^{1} v(x):=\frac{1}{2} \sum_{i=1}^{M} b_{i}(x)\left[\partial_{1} v(x)+\bar{\partial}_{i} v(x)\right]+o(x) v(x), \\
& I_{h} v(x):=L_{h}^{O} v(x)+L_{h}^{1} v(x) .
\end{aligned}
$$

Let $\Omega_{1 h}$ and $\Omega_{2 h}$ denote non-empty domain of $R_{h}^{M}$ and let $R_{h}^{M}=\Omega_{1 h} \cup \Omega_{2 h}, \Omega_{1 h} \cap \Omega_{2 h}=\phi$. We determine a seguenoe $\left\{U^{n}(x)\right\}$ for $x \in R_{h}^{M}, n \in Z$, such that $U^{O}(x)=\phi(x)$ for $x \in R_{h}^{N}$. The difference problem (3.1) will be approximated by the following schema

$$
\text { (3.2) }\left\{\begin{array}{l}
\frac{2}{\tau}\left[U_{(x)}^{n+\frac{1}{2}}-U_{(x)}^{n}\right]+I_{h}^{n+\frac{1}{2}} U_{(x)}^{n}=f_{(x)}^{n}, \text { if } x \in \Omega_{1 h}, \\
\frac{2}{\tau}\left[U_{(x)}^{n+\frac{1}{2}}-U_{(x)}^{n}\right]+I_{h}^{n+\frac{1}{2}} U_{(x)}^{n+\frac{1}{2}}=\frac{1}{2}\left[f^{n+1}(x)+f_{(x)}^{n}\right], \text { if } x \in \Omega_{2 h}, \\
\frac{2}{\tau}\left[U_{(x)}^{n+1}-U_{(x)}^{n+\frac{1}{2}}\right]+I_{h}^{n+\frac{1}{2}} U_{(x)}^{n+\frac{1}{2}}=\frac{1}{2}\left[f^{n+1}(x)+f_{(x)}^{n}\right], \text { if } x \in \Omega_{2 h}, \\
\frac{2}{\tau}\left[U_{(x)}^{n+1}-U_{(x)}^{n+\frac{1}{2}}\right]+I_{h}^{n+\frac{1}{2}} U_{(x)}^{n+1}=f_{(x)}^{n+1}, \text { if } x \in \Omega_{1 h}, \\
U_{(x)}^{0}=\varphi(x),
\end{array}\right.
$$


where $U^{n}(x):=u(x, n \tau)$. For the difference sohema (3.2) there holds the following theorem on equivalence, analogous to Theorem 2.1.

The or e m 3.1. The sequenoes $\left\{U^{n}(x)\right\}$ for $x \in R_{h}^{M}$, $n \in Z(0 \leqslant 2 n \leqslant N)$, satisfies the syatem of equation (3.2) iff the sequenos $\left\{U^{n}(x)\right\}$ satisfies the following differenoe equation

$$
\left\{\begin{array}{c}
\frac{1}{2}\left[U_{(x)}^{n+1}-U_{(x)}^{n}\right]+\frac{1}{2}\left[L_{h}^{n+\frac{1}{2}} U_{(x)}^{n+1}+L_{h}^{n+\frac{1}{2}} U_{(x)}^{n}\right]=\frac{1}{2}\left[f^{n}(x)+f_{(x)}^{n+1}\right], \\
\quad \text { for } x \in R_{h}^{M}, n=\frac{n-1}{0, N-1} \\
U_{(x)}^{0}=\varphi(x), \text { for } x \in R_{h}^{M} .
\end{array}\right.
$$

The proof is similar to that of Theorem 2.1.

Th $\theta$ or $\theta \mathrm{m}$ 3.2. If the functions $a_{i, j}, b_{i}, 0,1$ $(i, j=\overline{1, M})$ are continuous and bounded and

$$
\frac{\partial a_{i j}(x, t)}{\partial t} \in C(R,(O, T))
$$

then there extets a positive number $\tau_{*}$ dependent only on the norms of coefficients and such that for $\tau \in\left(0, t_{*}\right)$ the difference schema (3.2) is unoonditionally stable and approximates the problem (3.1) with order $O\left(\tau+h^{2}\right)$.

The proof of this theorem can be found in [5].

The schema (3.2) is unoonditionally stable but is not always open which is shown in the following theorem.

The or m 3.3. The echema (3.2) with the condition $\Omega_{1 h} \cap \Omega_{2 h}=\emptyset$ is open iff the funotions $a_{i f}(i \neq j)$ are identically zero and

$$
\begin{aligned}
& \Omega_{1 h}=\left\{x \in R_{h}^{M} ; x=\left(m_{1} h_{1}, \ldots, m_{M} h_{M}\right), \frac{1}{2}\left[\sum_{j=1}^{M} m_{j}-1\right] \in z\right\}, \\
& \Omega_{2 h}=\left\{x \in \dot{R}_{h}^{M} ; x=\left(m_{1} h_{1}, \ldots, m_{M} h_{M}\right), \frac{1}{2} \sum_{1=1}^{M} m_{j} \in z\right\} .
\end{aligned}
$$

The proof of this theorem is analogous to that of Theorem 3.3 in $[6]$. 


\section{BIBLIOGRA PHY}

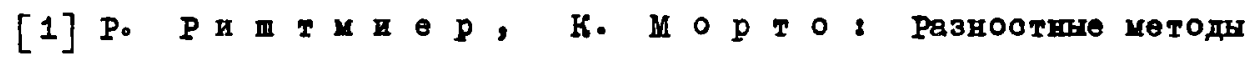
репения краевюх задач Москва 1972.

[z] B.K. II а у I $\odot$ в: 00 одном опособе чисденного интегри-

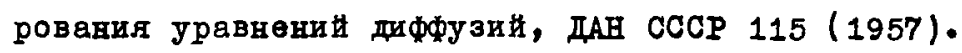

[3] В.K. II а у I- В : Интөгрирование уравненин параболического тина методом сеток. Москва 1960.

[4] И. П О т р о в С к и и : Разностно-дифферендиальные уравнения. PWN, Warszawa 1955.

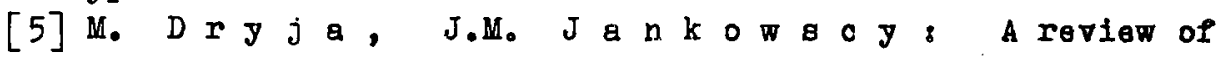
numerical methods and algorithms. WNT, Warszawa 1982, part II.

[6] V u V a n $\mathrm{H}$ u n $g:$ open, non-conditionally stabla differential schemas of solving boundary problems for parabolic equations of gecond order (Doctoral thesis in Poligh), Technical Univeraity of Warsaw, Warszawa 1986.

INSTITUTE OF MATHEMATICS, TECHNICAL UNIVERSITY OF WARSAW, 00-661 WARSZAWA

Received April 30, 1987; reviged version September 23, 1987. 
